\title{
A Case of IgA Vasculitis During Nivolumab Therapy for Renal Cell Carcinoma
}

\author{
Asami Nagaoka-Takatori (iD) \\ Madoka Ishii (D) \\ Koremasa Hayama (D) ${ }^{\prime}$ \\ Daisuke Obinata (iD ${ }^{2}$ \\ Kenya Yamaguchi iD ${ }^{2}$ \\ Satoru Takahashi iD ${ }^{2}$ \\ Hideki Fujita (D) \\ 'Division of Cutaneous Science, \\ Department of Dermatology, Nihon \\ University School of Medicine, Tokyo, \\ 173-86I0, Japan; ${ }^{2}$ Department of \\ Urology, Nihon University School of \\ Medicine, Tokyo, I73-8610, Japan
}

\begin{abstract}
A 50-year-old Japanese woman presented with a 4-day history of multiple purpura on her extremities and myalgia. She had been receiving nivolumab therapy for stage IV renal cell carcinoma for 18 months. Nivolumab was temporarily discontinued due to liver dysfunction and resumed 3 months before. Biopsy specimen revealed leukocytoclastic vasculitis, and direct immunofluorescence showed deposition of IgA and $\mathrm{C} 3$ in the vessel walls of the upper dermis. Based on these findings, a diagnosis of IgA vasculitis was made. She was treated with $20 \mathrm{mg}$ /day of oral prednisolone, which resulted in the complete disappearance of purpura and myalgia. Although the patient needed temporary cessation of nivolumab therapy, she experienced no recurrence of purpura or myalgia, and the dose of prednisolone was gradually tapered to $5 \mathrm{mg}$ /day. Although nivolumab can lead to various immune-related adverse events, vasculitis is rare. To the best of our knowledge, this is the second case of $\operatorname{IgA}$ vasculitis during nivolumab therapy.
\end{abstract}

Keywords: immune checkpoint inhibitors, leukocytoclastic vasculitis, PD-1, purpura

\section{Introduction}

Nivolumab is an immune checkpoint inhibitor (ICI) used for a variety of cancers. ICIs cause immune-related adverse events (irAEs) including diarrhea, colitis, hepatitis, skin toxicity, hypophysitis, and thyroid dysfunction. ${ }^{1}$ However, there have been few reports of vasculitis as irAE. Among them, cutaneous vasculitis is even rarer, and only one case of IgA vasculitis has been reported. ${ }^{2}$ Herein, we report IgA vasculitis during nivolumab therapy.

\section{Case Presentation}

A 50-year-old Japanese woman presented to our department with a 4-day history of multiple purpura on her extremities. She had been receiving nivolumab therapy (240 mg every 2 or 3 weeks) for stage IV renal cell carcinoma (T4N2M0) for 18 months. Nivolumab was temporarily discontinued due to common bile duct stone and liver dysfunction and resumed 3 months before. Liver dysfunction persisted even after treatment for common bile duct stones, hepatic irAE was diagnosed. The hepatic irAE had been successfully treated with $30 \mathrm{mg} /$ day of oral prednisolone (PSL), and the dose of PSL was reduced to $5 \mathrm{mg}$ /day at the onset of purpura. At presentation, there were numerous palpable and non-palpable purpura, approximately $3 \mathrm{~mm}$ in diameter, on the extremities (Figure 1). Although she had myalgia in her extremities, she
Correspondence: Hideki Fujita

Division of Cutaneous Science,

Department of Dermatology, Nihon

University School of Medicine, 30-I

Oyaguchi-Kamicho, Itabashi-ku, Tokyo,

173-8610, Japan

Tel +8I-3-3972-8III (ext. 2502)

Fax +8I-3-5995-984I

Email fujita.hideki@nihon-u.ac.jp 


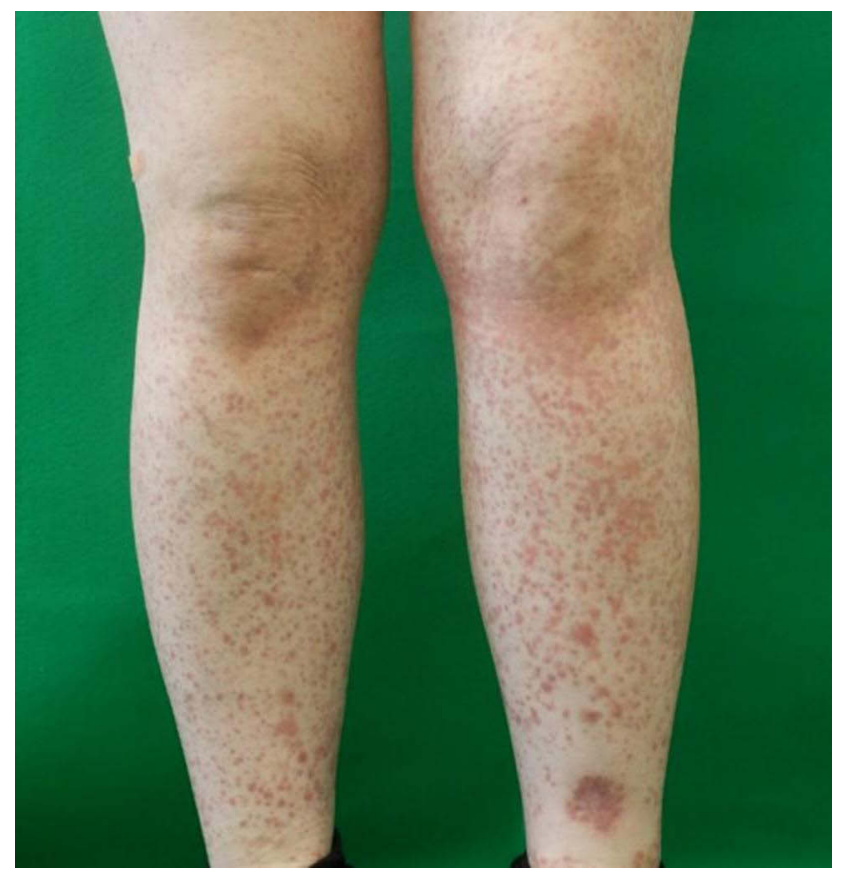

Figure I Numerous palpable and non-palpable purpura on the lower legs.

denied pyrexia, upper respiratory tract symptoms, abdominal pain, bloody stool, arthralgia, and gross hematuria. Laboratory examination revealed elevated C-reactive protein (CRP) $(5.59 \mathrm{mg} / \mathrm{dl})$ and $\operatorname{IgA}$ (425 $\mathrm{mg} / \mathrm{dl})$. Urinalysis showed $\mathrm{a} \pm$ test for protein and a $2+$ test for blood. Elevated CRP and occult hematuria were continuous and ascribable to renal cancer. Neither anti-neutrophil cytoplasmic antibodies nor cryoglobulins were detected in the patient's serum. Biopsy specimen from purpura on the right thigh revealed perivascular infiltration of neutrophils with

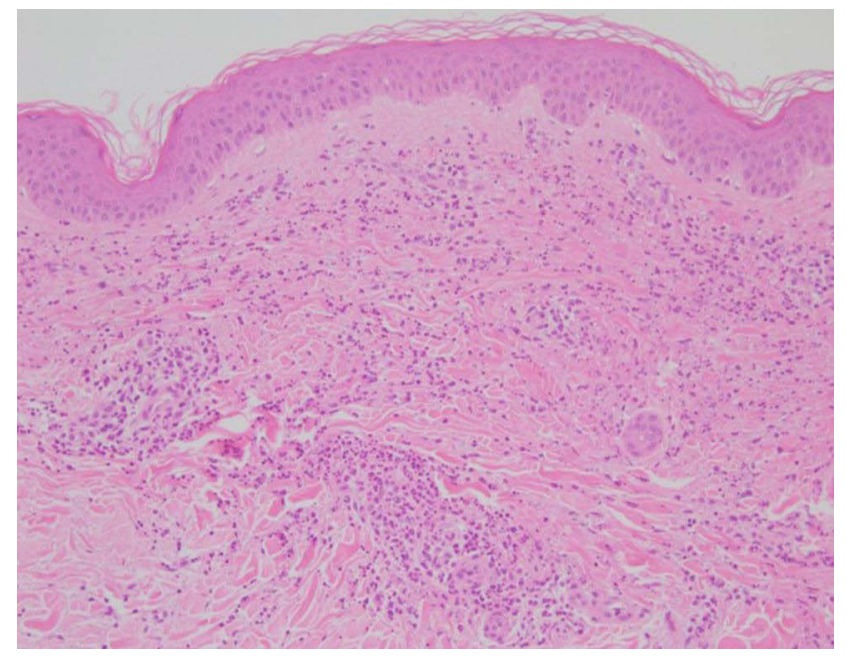

Figure 2 Histopathological features of the purpura. Perivascular neutrophil infiltration and nuclear dust deposition in the upper dermis. (H\&E staining, $\times 100$ ). nuclear dust and extravasated erythrocytes in the upper dermis (Figure 2), which was consistent with leukocytoclastic vasculitis. Direct immunofluorescence showed deposition of $\operatorname{IgA}$ and C3 in the vessel walls of the upper dermis (Figure 3A and B). Thus, a diagnosis of IgA vasculitis was made.

Her skin symptoms temporarily showed spontaneous improvement after discontinuation of nivolumab. PSL therapy for hepatic irAE was discontinued 2 weeks after the initial visit. Because purpura recurred after the termination of PSL, PSL was restarted at a dose of $20 \mathrm{mg}$ /day 4 weeks after the initial visit, which resulted in the complete disappearance of purpura and myalgia 3 months later. Serum IgA level had also been in the normal range. Although nivolumab therapy was resumed 2 weeks after re-initiation of PSL owing to the progression of renal cancer, the patient experienced no recurrence of purpura or myalgia, and the dose of PSL was gradually tapered to $5 \mathrm{mg}$ /day. Because of further progression of the tumor, her cancer treatment was changed from nivolumab to cabozantinib 5 months after the initial visit. Thereafter, her cancer progressed to cause lymph node enlargement, and her treatment was changed to nivolumab again 18 months after the initial visit without relapse of purpura under continuous $5 \mathrm{mg} /$ day of PSL.

\section{Discussion}

While ICIs cause various irAEs, there are few reports of vasculitis as irAE. Only five cases of cutaneous leukocytoclastic vasculitis during the treatment of programmed cell death protein 1 (PD-1) antibody nivolumab have been reported. Cutaneous leukocytoclastic vasculitis has also been reported in association with PD-1 antibody pembrolizumab monotherapy, ${ }^{3}$ as well as pembrolizumab plus anti-cytotoxic T-lymphocyte-associated antigen 4 (CTLA4) antibody ipilimumab combination therapy. ${ }^{4}$ There are only two cases of $\operatorname{IgA}$ vasculitis during the treatment of ICIs, one case is a patient with squamous cell carcinoma of the lung during the treatment of anti-programmed cell death ligand 1 (PD-L1) antibody durvalumab, ${ }^{5}$ the other case is a patient with metastatic melanoma during the treatment of nivolumab therapy. ${ }^{2}$ To the best of our knowledge, our case is the second case of $\operatorname{IgA}$ vasculitis while undergoing anti-PD-1 antibody therapy. We summarize the cases of IgA vasculitis during ICI therapy in Table 1. Systemic steroid treatment was performed in all cases. In two cases, ICI therapy for the primary disease was 


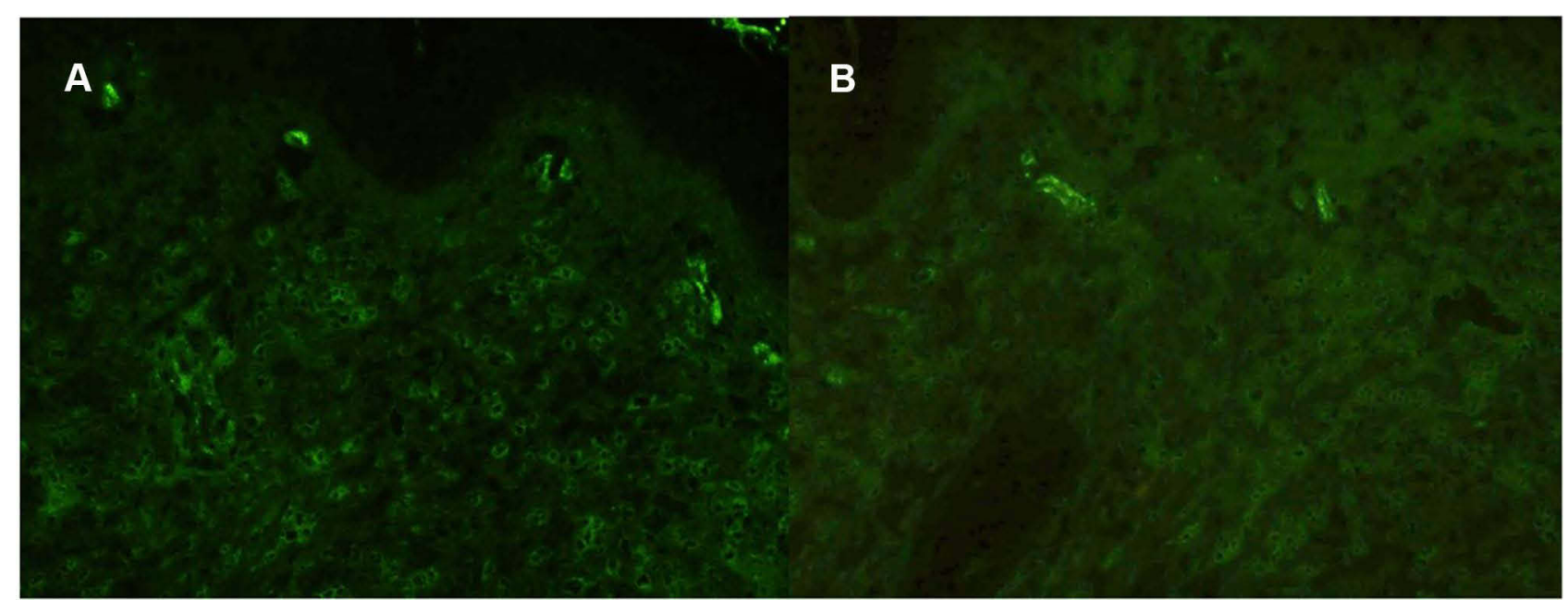

Figure 3 Direct immunofluorescence showed deposition of $\lg A(\mathbf{A})$ and C3 $(\mathbf{B})$ in the vessel walls of the upper dermis $(\times 200)$.

discontinued. It is unclear how ICIs contribute to the development and pathogenesis of $\operatorname{IgA}$ vasculitis. Although IgA vasculitis could be an accidental or malignancy-related condition rather than irAE in our case, further studies are needed to elucidate its pathophysiology in the course of ICI therapy.

\section{Ethics Statement}

Institutional approval was not required for this case report.

\section{Consent Statement}

Written informed consent was provided by the patient for publication of images and information.

Table I Three Cases of IgA Vasculitis During Immune Checkpoint Inhibitor Therapy

\begin{tabular}{|c|c|c|c|}
\hline & Our Case & 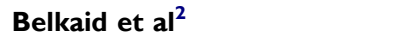 & Casafont-Solé et $\mathrm{al}^{5}$ \\
\hline Age (years), sex & 50 , female & 70, male & 64 , male \\
\hline Disease & Renal cell carcinoma & Metastatic melanoma & $\begin{array}{l}\text { Squamous cell carcinoma of the } \\
\text { lung }\end{array}$ \\
\hline $\mathrm{ICl}$ & Nivolumab & Nivolumab & Durvalumab \\
\hline $\begin{array}{l}\text { Treatment duration before IgA } \\
\text { vasculitis }\end{array}$ & $\begin{array}{l}25 \text { cycles ( } 5 \text { cycles after } \\
\text { resumption) }\end{array}$ & $\begin{array}{l}4 \text { cycles of nivolumab plus } \\
\text { ipilimumab and } 4 \text { cycles of } \\
\text { nivolumab monotherapy }\end{array}$ & 5 cycles \\
\hline Other irAEs & Liver dysfunction & No & Polymyalgia rheumatica \\
\hline $\begin{array}{l}\text { Other symptoms as } \lg A \text { vasculitis } \\
\text { except for skin }\end{array}$ & Myalgia & $\begin{array}{l}\text { Abdominal pain, diarrhea, } \\
\text { arthralgia, proteinuria, hematuria }\end{array}$ & Proteinuria, hematuria \\
\hline Cessation of ICl & Temporary & Yes & Yes \\
\hline Treatment & Oral PSL & $\begin{array}{l}\text { Intravenous boluses of } \\
\text { methylprednisolone, oral PSL }\end{array}$ & Oral PSL \\
\hline
\end{tabular}

Abbreviations: ICl, immune checkpoint inhibitor; irAEs, immune-related adverse events; PSL, prednisolone; PD-I, programmed cell death protein I; CTLA-4, cytotoxic T-lymphocyte-associated antigen 4; PD-LI, programmed cell death ligand I. 


\section{Disclosure}

The authors report no conflicts of interest in this work.

\section{References}

1. Spain L, Diem S, Larkin J. Management of toxicities of immune checkpoint inhibitors. Cancer Treat Rev. 2016;44:51-60. doi:10.1016/j.ctrv.2016.02.001

2. Belkaid S, Berger M, Nouvier M, Picard C, Dalle S. A case of Schönlein-Henoch purpura induced by immune checkpoint inhibitor in a patient with metastatic melanoma. Eur $J$ Cancer. 2020;139:169-172. doi:10.1016/j.ejca.2020.08.005
3. Tomelleri A, Campochiaro C, De Luca G, Cavalli G, Dagna L. Anti-PD-1 therapy-associated cutaneous leucocytoclastic vasculitis: a case series. Eur J Intern Med. 2018;57:e11-e12. doi:10.1016/j.ejim.2018.07.023

4. Castillo B, Gibbs J, Brohl AS, Seminario-Vidal L. Checkpoint inhibitor-associated cutaneous small vessel vasculitis. J Am Acad Dermatol. 2018;4:675-677.

5. Casafont-Solé I, Martínez-Morillo M, Camins-Fàbregas J, BrandyGarcía A, Quer A, Moran T. IgA vasculitis and polymyalgia rheumatica induced by durvalumab. Transl Lung Cancer Res. 2020;9 (2):421-423. doi:10.21037/tlcr.2020.03.01

\section{Publish your work in this journal}

Clinical, Cosmetic and Investigational Dermatology is an international, peer-reviewed, open access, online journal that focuses on the latest clinical and experimental research in all aspects of skin disease and cosmetic interventions. This journal is indexed on CAS.
The manuscript management system is completely online and includes a very quick and fair peer-review system, which is all easy to use. Visit http://www.dovepress.com/testimonials.php to read real quotes from published authors. 